\title{
Childhood multiple sclerosis with psychotic manifestations
}

\author{
LUIS F. SALGUERO, HIDEO H. ITABASHI, ${ }^{1}$ AND NORMA B. GUTIERREZ \\ From the Departments of Neurology and Pathology, University of Michigan Medical School, \\ Ann Arbor and Ypsilanti State Hospital, Ypsilanti, Michigan, U.S.A.
}

Mental symptoms such as disturbances of mood, affect, and intellectual function in multiple sclerosis are well known. Although actual psychotic manifestations are rare, there are several reports in the literature of patients with multiple sclerosis who, in the course of their disease or preceding it, developed psychotic symptoms (Howes, 1927; Arbuse, 1938; Langworthy, Kolb, and Androp, 1941; Teitelbaum, Hall, and Phillips, 1952; Parker, 1956; Bergin, 1957; Cremieux, Alliez, Toga, and Pache, 1959; Bignami, Gherardi, and Gallo, 1961; Ivers and Goldstein, 1963; Můr, Kümpel, and Dostál, 1966). Secondly, multiple sclerosis is uncommon in children, although there are several reports of childhood multiple sclerosis in the literature (Low and Carter, 1956; Isler, 1961; Kennedy and Carter 1961; Kuroiwa, Inoue, Araki, and Inoue, 1962; Paine, Goodman, Houck, and Javedan, 1963). Müller (1949) found in his series of 810 patients three $(0.37 \%)$ whose illness began between the ages of 5 and 9 years; Gall, Hayles, Siekert, and Keith (1958) found an incidence of $0.4 \%$. We report here a case of multiple sclerosis in an 11-year-old girl who showed unusual mental symptoms. The pathoanatomical lesions are presented and interpreted in the light of the clinical symptoms, especially in respect to the mental changes.

\section{CASE REPORT}

An 81-year-old girl of Mexican ancestry was admitted to the University of Michigan Hospital in November 1965 because of gradual onset of blindness over a period of one month. She was born uneventfully after a seven month gestation. Birth weight was $4 \mathrm{lb} 3 \mathrm{oz}(1.92 \mathrm{~kg})$. She was in an incubator for four weeks and then discharged home in good condition. She sat up at 6 months of age and walked at 18 months. Her health remained good, and she attended regular school until the end of September 1965, when frontal headaches and blurred vision developed. She became increasingly inattentive

${ }^{1}$ Reprint requests to Dr. Itabashi, 1405 East Ann Street, Ann Arbor, Michigan 48104, U.S.A. and fell asleep for short periods and seemed uninterested and unwilling to participate in games. On 13 October, because of alleged sexual assault upon her by a man in the neighbourhood, she was admitted to a local hospital. Examination revealed no evidence of rape. Ataxia, however, and decreased vision were found. Radiographs of the skull were normal. Most examiners thought the blindness to be an hysterical symptom, but the psychiatrist felt that it was organic.

On admission her weight was $50 \mathrm{lb}(22.7 \mathrm{~kg})$, height 50 in. $(1.3 \mathrm{~m})$, and head circumference 20 in. $(0.51 \mathrm{~m})$. General physical examination was normal. She was alert, oriented, and cooperative, but she was apprehensive and complained that she could not see. She counted fingers with the right eye, and there was light perception on the left. Disk margins were sharp with good colour, and retinal vessels were normal. Central vision was impaired bilaterally but she did appear to have some peripheral vision. Pupils were large but reacted to light. There was good muscle tone and strength bilaterally. Her gait was mildly ataxic. Heel-to-shin test was done poorly bilaterally, but finger-to-nose test was normal. Sensations were normal. Deep tendon reflexes were normal in the upper extremities and increased in the legs bilaterally. Babinski signs were present bilaterally.

Routine blood studies and urinalysis were negative. An EEG was mildly and diffusely abnormal, due to mild theta slowing. There was no visual evoked response. Radiographs of the skull, including views of the optic foramina, were negative, and brain scan was normal. Initial pressure on lumbar puncture was $150 \mathrm{~mm} \mathrm{H}_{2} \mathrm{O}$. The fluid was crystal clear and contained no cells; the total protein was $33 \mathrm{mg} / 100 \mathrm{ml}$. VDRL was negative, and the colloidal gold curve was flat. Cultures of the cerebrospinal fluid for bacteria and viruses were negative. On psychometric evaluation, her overall intellectual functions were interpreted as being just below the average level; immediate recall was her poorest performance. Because a demyelinative disorder was suspected, the patient was treated with methylprednisolone, $24 \mathrm{mg}$ per day. Two weeks later she was less ataxic and the Babinski signs had disappeared, and she was discharged.

Over the next several months her visual acuity improved and her ataxia disappeared. Steroids were discontinued. She returned to school. In July 1966, about seven months after discharge, she complained of urgency and frequency of urination and paraesthesias in the right 
arm. She had become irritable, weepy and dependent, and 'hard to care for'. She was readmitted to the University Hospital. There was ataxia of the left extremities and dysdiadokokinesis on the right side. Although fundi were normal, vision was moderately impaired. Deep reflexes were increased on the right side, and a Babinski sign was present bilaterally. Cerebrospinal fluid was again normal.

While in the hospital she was seductive, manipulative, and responded at times in a pseudo-mature way and, at other times, in a very infantile and inappropriate manner. The psychiatrist's opinion was that she had a hysterical personality with underlying depression. Apart from her organic illness, he thought the seriousness of her separate personality disorder required in-patient psychiatric treatment, and she was transferred to the psychiatric unit.

During the first month of hospitalization, the patient was regarded as a very depressed, seductive, manipulative child with fears of dying and separation. She had enuresis. Her chief mechanism of defence was strong denial. She related very poorly with peers and staff and became actively aggressive, angrily striking staff, peers, and teachers without provocation. Her condition worsened to that of psychotic behaviour with almost no impulse control. She was demanding and narcissistic and became extremely aggressive when denied gratification. She described auditory and visual hallucinations of monsters trying to harm her. When she became unable to walk and talk after being given trifluoperazine hydrochloride, $8 \mathrm{mg}$ daily for two days, the drug was discontinued, and she was transferred to the paediatric service. Early optic atrophy, absent pupillary light reflexes, and left exotropia were found. There was marked terminal tremor of the left hand, plastic rigidity of all extremities, and a grasp reflex on the left. A snout reflex was present, and Babinski signs were noted bilaterally. An EEG was markedly abnormal and compatible with a diffuse encephalopathy; a brain scan was normal. Twenty-four hours after drug withdrawal she was alert, talking and walking, and she was transferred back to the psychiatric unit.

Chlordiazepoxide hydrochloride was given in gradually increasing dosage to $60 \mathrm{mg}$ per day. Her aggressiveness, however, became progressively worse, although she was still able to interact appropriately with peers and staff. She expressed fear of being separated from individuals by grasping, clutching, and scratching. In late November 1966, the chlordiazepoxide was discontinued, and her activities had to be reduced to a minimum and her supervision to a more or less one-to-one attention. Because of disruptions due to her extreme behavioural disturbance, she was discharged to an institution for emotionally disturbed children in January 1967.

In the state hospital she was placed on individual therapy and was started on several medications including: diphenhydramine hydrochloride, $10 \mathrm{mg}$ four times daily, thioridazine hydrochloride, $25 \mathrm{mg}$ twice daily, and ascorbic acid, $100 \mathrm{mg}$ three times daily. Although she was alert and oriented, irritability and short attention span were noted. Her behaviour was unpredictable in that she often approached the examiner and others very politely with a formal and warm demeanour and then suddenly jumped, bit, and kicked as soon as she was close.
She had a 'peculiar' spastic gait, truncal ataxia, and a resting tremor in all extremities resembling that of Parkinson's disease.

The patient had a brief admission to the University Hospital in March 1967 for further studies. Cerebrospinal fluid and pneumoencephalography were normal. The EEG was mildly abnormal because of excessive rhythmic sharp theta activity. Rectal biopsy showed normal ganglion cell of the myenteric plexus.

The patient was transferred back to the state hospital, and in October 1967 she developed rapid bilateral horizontal nystagmus. Her speech was slow and of scanning type. She drooled constantly and, with increasing difficulty in swallowing, she frequently choked on solid foods. Her vision remained moderately to severely impaired as assessed by her behaviour. Ataxia of her left extremities continued to be prominent. Later, hypotonia and weakness of the right arm and small muscle atrophy of the right hand were noted. She masturbated openly and seemed preoccupied with sexual matters. Her extremely combative behaviour, spitting, urinating, defaecating, and smearing of faeces were interpreted as expressions of aggression.

The course was downhill; she lost weight and developed stomatitis. The nurses had difficulty in feeding her, and finally, intravenous feedings were required. In February 1968 her family requested that she be discharged. She died at home on 3 April 1968, at the age of 11 years, after a brief respiratory illness.

PATHological Findings At necropsy, the body was generally and markedly wasted and weighed $45 \mathrm{lb}$ $(20.4 \mathrm{~kg})$. The significant general finding was a panlobar confluent, suppurative, and haemorrhagic pneumonia which was the cause of death. Pinhead-sized atheromatous plaques were noted in the endocardium and the aortic wall below and above the valves, respectively, and were confirmed microscopically.

The brain weighed $1,130 \mathrm{~g}$ and was externally normal. Sections revealed multiple, disseminated, grey-white lesions within the thalamus and basal ganglia with irregular outlines and measuring up to $5 \mathrm{~mm}$ in diameter. The ventricles were of normal size. Leptomeninges, blood vessels, brain-stem, cerebellum, and cranial nerves were grossly normal.

Microscopically, demyelinative plaques were present at all levels of the central nervous system. Although not grossly noted, isolated plaques were found in cerebral white matter in the occipital lobe and the orbito-frontal lobe. Small plaques were present in the putamen and the adjacent anterior limb of the internal capsule, the globus pallidus just above the anterior commissure and extending medially to involve the most ventral part of the internal capsule, the stria terminalis and parolfactory area (Fig. 1). The adjacent fornix was spared. On both sides, there were multiple plaques in the dorsal thalamus, including the nucleus centrum medianum, red nuclei, substantia nigra, and adjacent internal capsule and peduncles. Plaques also involved the fasciculus lenticularis and the subthalamic nuclei to a lesser extent (Figs. 2 and 3). The bilateral lesions in the hippocampus proper were small and affected portions of the alveus 


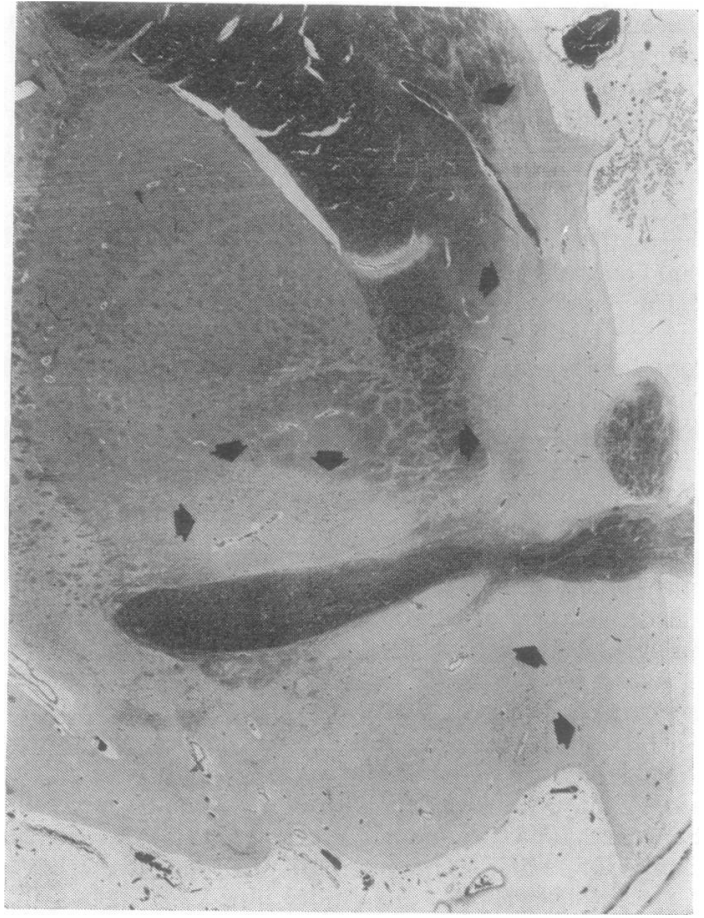

FIG. 1. Macrograph at the level of anterior commissure showing complex demyelinative plaques involving the globus pallidus just above the anterior commissure, ventral-most portion of anterior limb of internal capsule and stria terminalis and the parolfactory area (outlined by arrows). The fornix is spared. Klüver-Barrera stain.

and the pyramidal layer (Figs. 2 and 3). Larger and more discrete lesions involved the posterior hippocampus (Fig. 4) and the parahippocampal gyrus, including destruction of the tracts leading into the hippocampus proper. A smaller lesion involved the alveus at its junction with the fimbria.

Both optic tracts contained symmetrical plaques destroying about $50 \%$ of them. At the level of the optic chiasm and nerves, there was nearly total demyelination (Fig. 5). In the pons, almost the entire tegmentum on one side and the brachium conjunctivum on the opposite side were replaced by plaques (Fig. 6). Portions of the medial reticular grey and the nucleus ambiguous symmetrically on both sides were included in the demyelinative process.

In the spinal cord, at the level of the upper cervical region, there were large plaques in the mid-portion of the posterior columns and in the anterolateral funiculus on one side (Fig. 7). A less discrete plaque was noted on the opposite side. At the lower cervical level, both lateral corticospinal tracts were completely demyelinated. Thoracic and lumbar portions of the spinal cord contained no lesions, but there was mild, probably Wallerian, degeneration of the lateral corticospinal tracts.

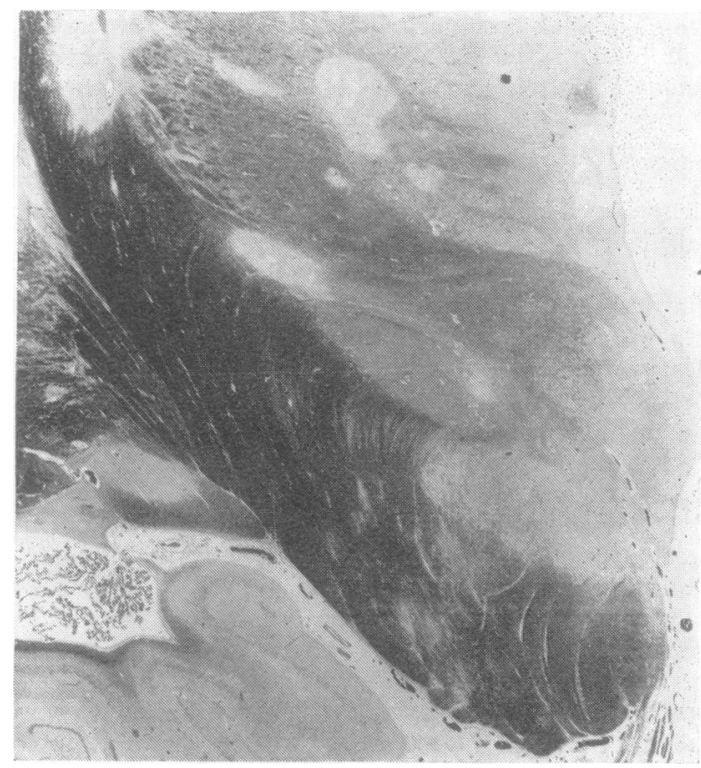

FIG. 2. Macrograph at the level of red nucleus showing multiple plaques. Klüver-Barrera stain.

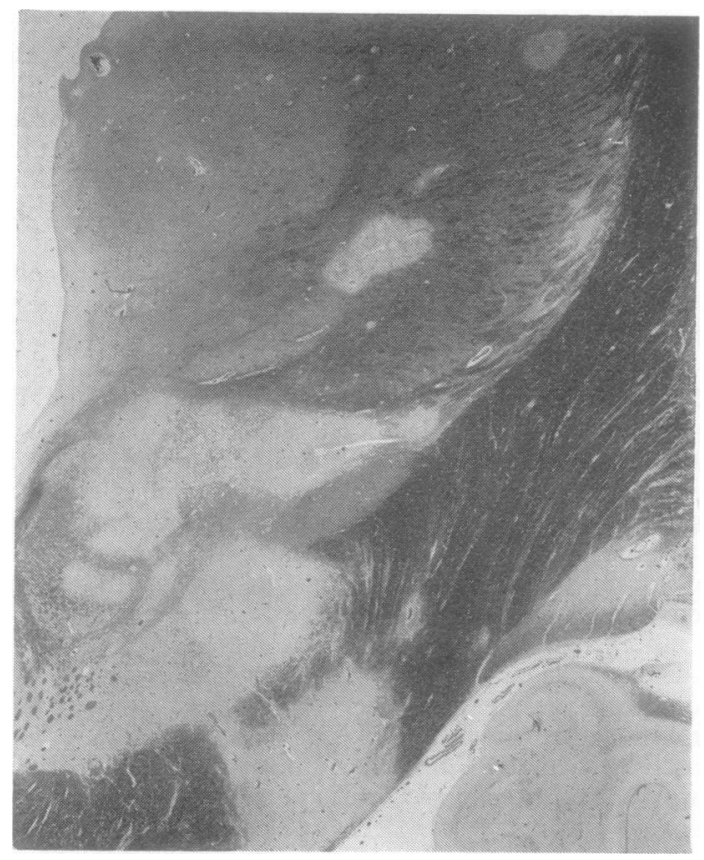

FIG. 3. Macrograph at the same level as Fig. 2 on the opposite side. Klüver-Barrera stain. 


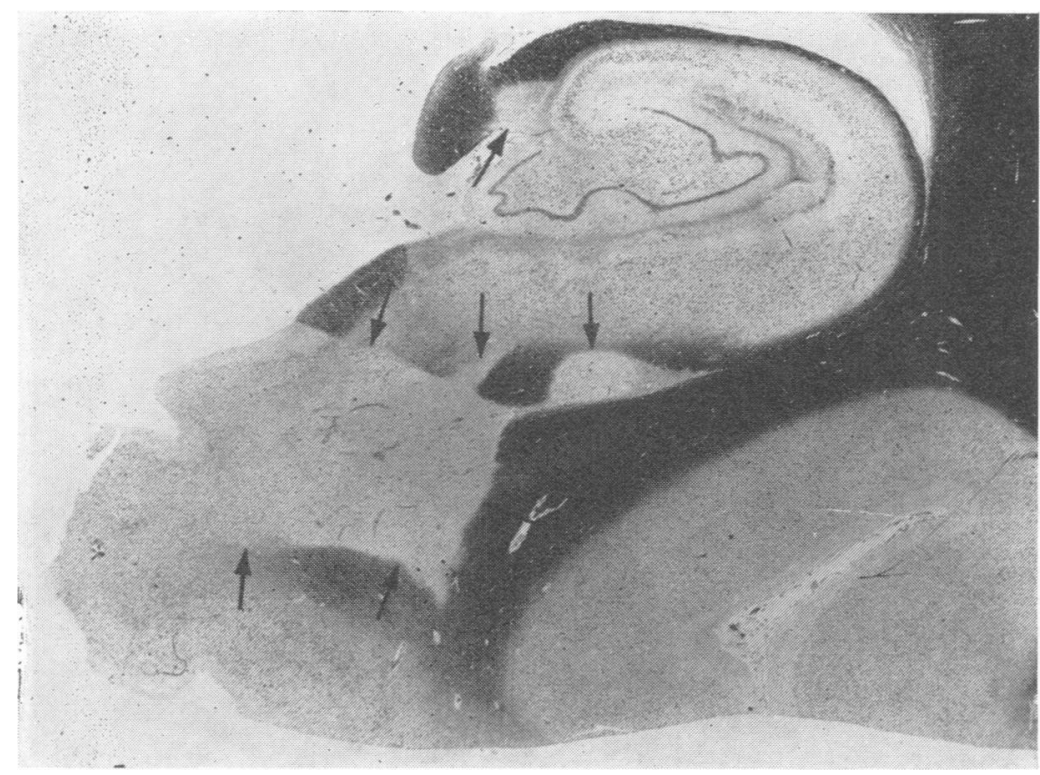

FIG. 4. Hippocampal formation showing plaques in the alveus and parahippocampal gyrus (outlined by arrow's). KlüverBarrera stain.

Histologically, the findings were characteristic of the plaques of multiple sclerosis. The demyelinated margins were most often discrete and not confined to white matter but extended into grey nuclei without respect to anatomical boundaries. They were often perivenous and sometimes contained perivascular mononuclear inflammatory cells and lipomacrophages. Grey nuclei within the plaques showed relative preservation of neurones, and even severely demyelinated plaques with fibrous gliosis showed good preservation of axons (Fig. 8). The margins of the plaques appeared hypercellular due to an excess of rod cells (microglia).

\section{REVIEW OF THE LITERATURE}

The pathogenesis of the mental symptoms such as euphoria, intellectual deterioration, and depression in multiple sclerosis has not yet been conclusively demonstrated. Various authors have given different interpretations for the source of such symptoms. Dercum (1912) reported the case of a 20-year-old man with severe multiple sclerosis who had marked loss of memory, euphoria, and foolish behaviour from the onset of his illness. Lesions of multiple sclerosis were scattered throughout various parts of the nervous system. The author expressed the belief that the mental symptoms were secondary to small areas of sclerosis in the cortical and subcortical areas of the frontal, parietal and temporal lobes.

Cottrell and Wilson (1926) studied 100 consecutive patients with multiple sclerosis and found euphoria in $63 \%$, depression in $10 \%$, variable affective symptoms in $13 \%$, and indifference in $2 \%$. There was intellectual deterioration in only two cases. They concluded that the relative preservation of the intellectual faculties was due to sparing of the cortex and attributed the affective symptoms to periventricular lesions, although no pathological material was presented.

Langworthy et al. (1941) studied 199 patients with multiple sclerosis of whom 16 were finally committed to psychiatric hospitals. Ten patients were reported on in detail and classified as follows: (1) those with symptoms of hysteria, (2) those with difficult social adjustment, and (3) those with mild and major behavioural difficulties. Three (1.5\%) showed major behavioural disturbances. The first was a 27-year-old man who developed emotional instability, euphoria, uncontrollable temper, sexual indiscretions, and exhibitionism. The second was a 52-year-old woman who had confusion, paranoid trends, and slight memory deterioration. The last patient was a 27 -year-old man who exhibited some mental deterioration, irritability, noisiness, stubborness, and pugnacity. These authors interpreted the euphoria as being due to interruption of the projection fibres of the frontal lobes. On the other hand, symptoms of depression, hypomania, paranoid trends, and grandiose psychoses were attributed to a psychopathology dependent upon the prior personality make-up and not to brain pathology. More of their patients were committed to a psychiatric hospital for behavioural disturbance than for dementia, and, although they interpreted the infracortical white matter plaques in the forebrain 

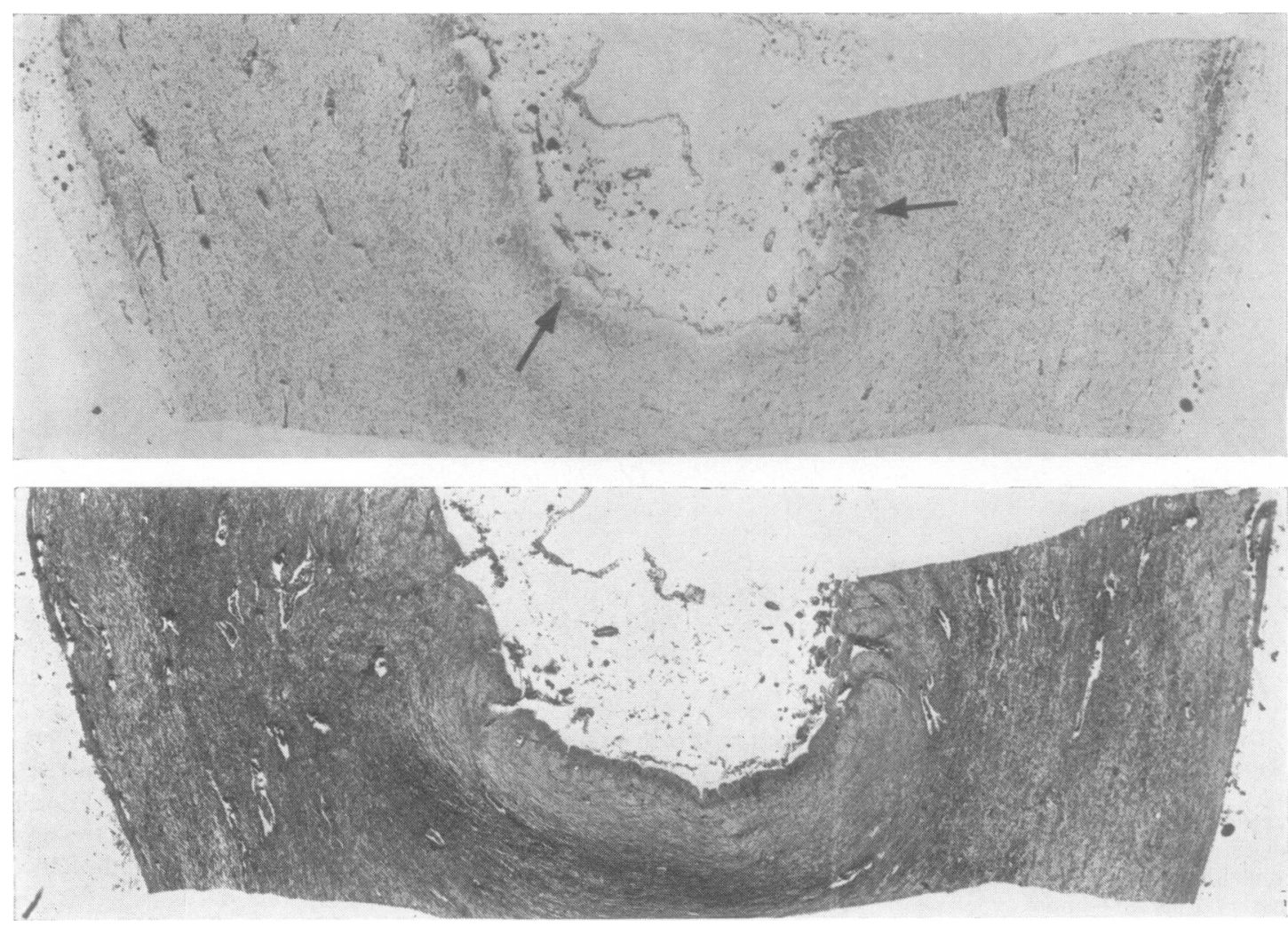

FIG. 5. Optic chiasm. (Above) Myelin stain shows total demyelination. Arrows point to the only surviving myelinatedō fibres. (Below) Same section with glial stain showing dense fibrosts. Klüver-Barrera and phosphotungstic acid haematoxylin? stains.

as the cause of dementia, no precise explanation for the behavioural disturbances was given. There was no pathological material.

Braceland and Giffin (1950) did a clinical study of 75 multiple sclerosis patients between the ages of 18 and 58 years. Ten per cent of them were classified as euphoric; $20 \%$ as depressed; $18 \%$ showed lability of mood; and $12 \%$ were unusually irritable. The remaining $40 \%$ reacted appropriately to their disease. The authors concluded that the patient reacts to his disease in a manner which to some degree depends on his personality make-up, with some modifying factors such as the number, extent, and location of the lesions, his physical handicap and its significance to him.

Ross and Reitan (1955) compared 13 patients with multiple sclerosis with two control groups, one of patients with various types of proven brain damage and the other of patients with no history or evidence of brain damage. The tests administered were the Minnesota Multiphasic Personality Inventory, Halstead's tests for measurement of 'biologic intelligence' and the Rorschach test. On the Minnesota test all groups were similar. The Halstead's test indicated severe and parallel intellectual impairment in a high percentage of multiple sclerosis and brain damaged patients. The Rorschach test indicated similar impairment but of less striking magnitude. The Wechsler-Bellevue fullscale intelligence quotient test was given to all groups and the mean IQ was similar in all of them. They concluded that there is a high percentage of affective and intellectual disturbances in multiple sclerosis patients.

Parker (1956) reported on a patient diagnosed as being schizophrenic who died of multiple sclerosis at the age of 29 years. One year before death his IQ had dropped to 51. His affect was inappropriate and general apathy was prominent. The brain showed widespread lesions but unfortunately anatomical details were not reported, and the author 


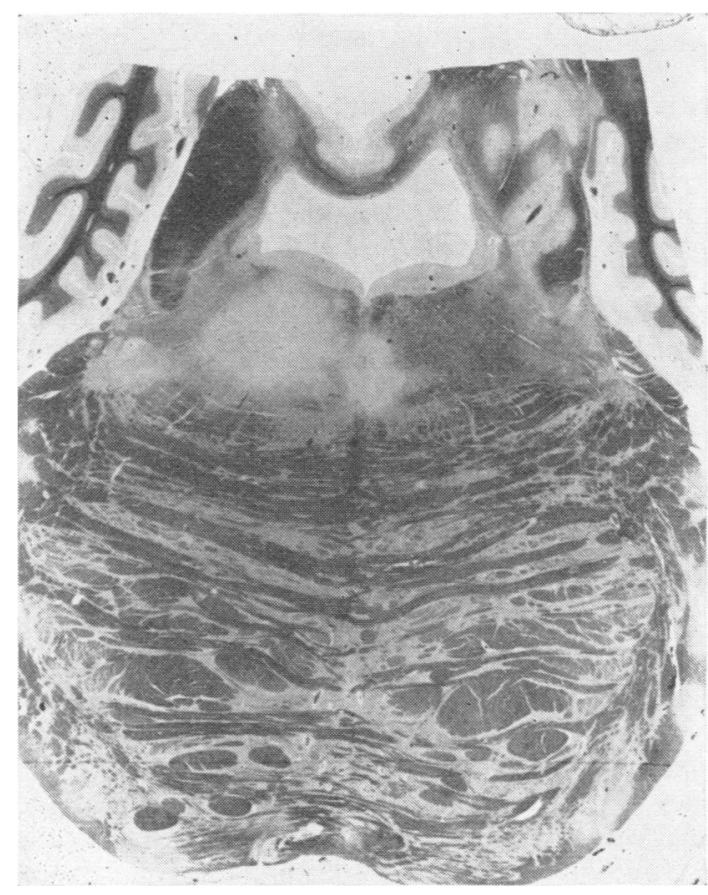

FIG. 6. Pons showing lesions in the tegmentum and brachium conjunctivum. Klüver-Barrera stain.

implied that the mental symptoms were those associated with and not due to the disease.

Bergin (1957) reported on two patients with multiple sclerosis and rapidly progressing dementia and behaviour disturbances. Unfortunately, no necropsy was obtained in case 2 . The first patient

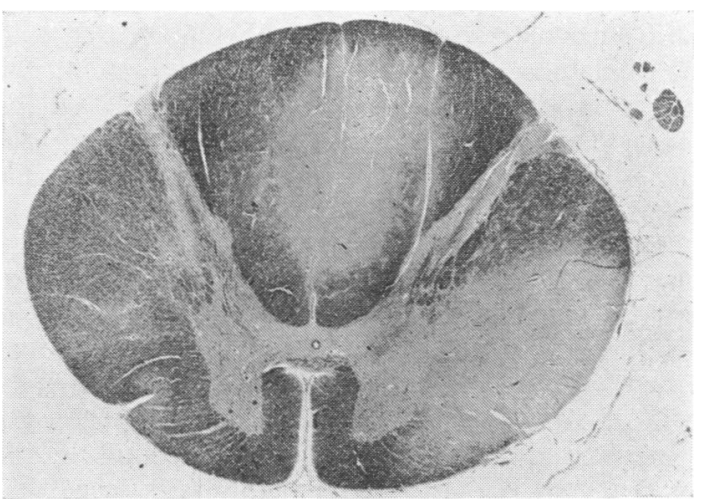

FIG. 7. Plaques in the central portion of posterior columns and anterolateral funiculus on one side of spinal cord. Klüver-Barrera stain.

was a 32-year-old woman who had gait difficulties and who later became confused, disoriented, and uncooperative. Within a few days she became markedly demented. Widespread plaques were found in the central white matter of the cerebral hemispheres, cerebellum, brain-stem, and spinal cord. The mental changes and altered consciousness were attributed to the widespread lesions of the cerebral hemispheres and brain-stem.

Cremieux et al. (1959) reported on a 47-year-old man who developed insomnia and depression and was committed to an institution. At that time no neurological abnormalities were noted; however, two years after the onset of his mental symptoms, signs of multiple sclerosis developed. The brain showed disseminated lesions in centrum ovale,

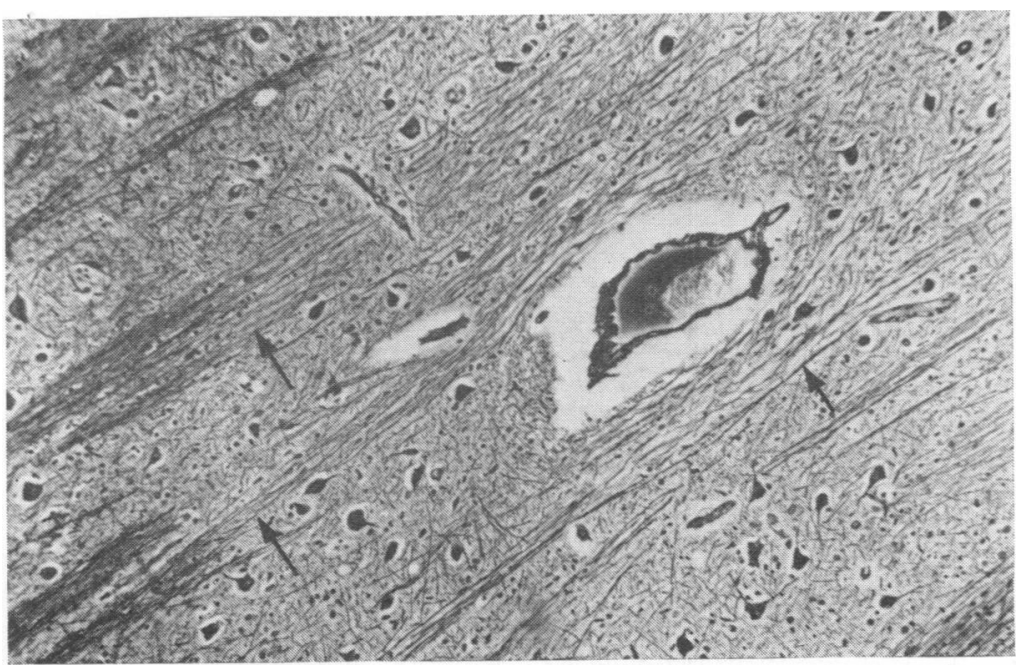

FIG. 8. Detail of plaque margin showing sharp demyelination and preservation of axons (arrows) and nerve cell bodies within the plaque zone. Luxol fust bluesilver stain, $\times 90$. 
paraventricular zones, temporal white matter, and the thalamus. The authors were cautious in the interpretation of the meaning of the role of the anatomical lesions in causing the mental change but suggested that these lesions may have modified the patient's premorbid personality.

Bignami et al. (1961) described a 22-year-old man who developed insomnia, asthenia, and frequent crying. After 10 days in a psychiatric hospital he developed neurological abnormalities consistent with multiple sclerosis for the first time. The total duration of his disease was two months. At necropsy a large area of demyelination was found in the hypothalamus bilaterally. The authors believed that the anatomical lesions were the cause of the symptoms and pointed out the relationship between the hypothalamus and diencephalic structures and the emotional-affective life.

McAlpine, Lumsden, and Acheson (1965) reported on a 20-year-old woman who became disinclined to do anything and had paraesthesias and slight weakness of one foot. A few days later she had auditory and visual hallucinations and became more withdrawn and difficult to handle. These symptoms subsided, but she later developed other signs supporting the diagnosis of multiple sclerosis. There was no post-mortem examination.

Můr et al. (1966) reported three women, aged 68, 60 , and 58 years, in whom multiple sclerosis manifested as psychosis, two as paranoia and one as depression. Plaques were located in periventricular areas and frontal lobes in all. Since the same morphological substrate was present in each of the cases, they excluded the possibility that the psychosis could be endogenous and only coincidental with multiple sclerosis.

Other cases of multiple sclerosis with interesting mental symptoms have been reported, but they lack pathological confirmation or details of the anatomical site of involvement (Howes, 1927; Arbuse, 1938; Sugar and Nadell, 1943; Teitelbaum et al., 1952; McAlpine, Compston, and Lumsden, 1955; Gallineck and Kalinowsky, 1958).

In children with multiple sclerosis reported in the literature, mental changes are not mentioned, absent (Low and Carter, 1956; Kuroiwa et al., 1962; Paine et al., 1963), or when present were not severe. One of Isler's (1961) eight patients showed intellectual deterioration but the degree was not mentioned. Gall et al. (1958) found mental changes in nine out of 40 children reported with multiple sclerosis. Four had euphoria and four were described as either 'giggly', depressed, or emotionally unstable. One other patient was confused to semi-stuporous on admission but recovered normal alertness within a few days.
DISCUSSION

As is characteristic of multiple sclerosis, the lesions were widely disseminated in this case. It is difficult to assign the mental dysfunctions to specific anatomical lesions in this disease, and caution should be displayed in their interpretation. Nevertheless, the attempt to correlate mental dysfunctions with anatomical lesions in this disease has been made before in some extremely interesting and, we believe, important cases (Bergin, 1957; Cremieux et al., 1959; Bignami et al., 1961).

Of the multiple neurological signs which our patient manifested-including optic atrophy, spastic gait, hyperreflexia, Babinski signs, ataxia, tremors of intention and Parkinsonian types, symptoms of a spastic bladder, and dysphagia-adequate anatomical lesions were demonstrated to account for most of them. For instance, excellent correlation was found between the visual loss and optic atrophy and total demyelination of the optic chiasm and nerves which also extended into the optic tracts on both sides. Intention and Parkinsonian tremors could have been secondary to brachium conjunctivum and red nucleus lesions and substantia nigra involvements respectively. Dysphagia was most probably the result of the demyelination of both of the nucle ambigui and their efferent fibres.

The mental symptoms of marked aggressive behaviour, memory impairment, oral tendencies? dependency, expression of fear, and apprehensione are those which may result from lesions of the? limbic system, in which extensive lesions were found. Aggressive behaviour has been found both in experimental animals and in human cases with lesions involving the ventromedial hypothalamic nucleus (John, 1951; Ingram, 1956, 1958), amygdala (Woringer, Thomalske, and Klinger, 1953; Kaada, Andersen, and Jansen, 1954; Sawa, Ueki, Arita, and Harada, 1954) and hippocampus (MacLean, 1954; Papez, 1958; Faris, 1969) among other areas. Memory impairment, especially immediate and recent intermediate memory, due to bilateral hippocampal lesions is well known and need not be reviewed here (DeJong, Itabashi, and Olson, 1969). The patient's memory deficit probably can be explained by the partial bilateral hippocampal lesions.

The patient's dependency, fear, and apprehension may have been due to the lesions found in the hippocampus, a structure that receives numerous transcortical impressions from all areas of the surrounding brain (Papez, 1958) and amygdala (Sugar and Nadell, 1943; Kaada et al., 1954; Heath, Monroe, and Mickle, 1955; Narabayashi and Uno, 1966; Heimburger, Whitlock, and Kalsbeck, 1966). In- 
attention, visual and auditory hallucinations, and seductive and manipulative behaviour are those of higher cortical functions for which we find no ready explanation in the observed lesions. As a matter of fact, the distribution of the demyelinative lesions were somewhat atypical in the relative absence of central white matter plaques. The usual periventricuiar plaques were absent, and there were only isolated plaques in the frontal and occipital white matter. The possible drug effect of thioridazine hydrochloride, trifluoperazine hydrochloride, methylprednisolone, and chlordiazepoxide hydrochloride also had to be taken into consideration in the assessment of inattention, irritability, memory impairment, and even tremors.

From the observations presented above, we conclude that this patient's unusual mental symptoms were mainly due to destructive demyelinative lesions in the limbic system and the hypothalamus, which are important anatomical substrates of emotion and behaviour.

\section{SUMMARY}

This is a case report of an 11-year-old girl with multiple sclerosis who, apart from visual, motor, and sensory impairments, manifested unusual psychotic symptoms as part of her disease. In addition to characteristic lesions in the optic chiasm and tracts, pons, and spinal cord, lesions were found in the basal ganglia, thalamus, hypothalamus, and hippocampus. It is postulated that the mental and affective symptoms developed secondary to involvement of the limbic system and hypothalamus.

The authors acknowledge and thank Dr. Russell N. DeJong for his helpful criticisms and encouragement.

\section{REFERENCES}

Arbuse, D. I. (1938). Psychotic manifestations in disseminated sclerosis. J. Mt Sinai Hosp., 5, 403-410.

Bergin, J. D. (1957). Rapidly progressing dementia in disseminated sclerosis. J. Neurol. Neurosurg. Psychiat., 20, 285-292.

Bignami, A., Gherardi, D., and Gallo, G. (1961). Sclerosi a placche acuta a localizzazione ipotalamica con sintomatologia psichica di tipo malinconico. Riv. Neurol., 31, 240-268.

Braceland, F. J., and Giffin, M. E. (1950). The mental changes associated with multiple sclerosis (an interim report). Res. Publ. Ass. nerv. ment. Dis., 28, 450-455.

Cottrell, S. S., and Wilson, S A. K. (1926). The affective symptomatology of disseminated sclerosis. J. Neurol. Psychopath., 7, 1-30.

Cremieux, A., Alliez, J , Toga. M., and Pache, R. (1959). Sclerose en plaques à debut par troubles mentaux. Etude Anatomoclinique. Rev. neurol., 101, 45-51.

DeJong, R. N., Itabashi, H. H., and Olson, J. R. (1969). Memory loss due to hippocampal lesions. Arch. Neurol. (Chic.), 20, 339-348.

Dercum, F. X. (1912). A case of multiple cerebrospinal sclerosis, presenting unusual symptoms suggesting paresis. J. Amer. med. Ass., 59, 1612-1613.

Faris, A. A. (1969). Limbic system infarction. A report of two cases. Neurology (Minneap.), 19, 91-96.
Gall, J. C., Hayles, A. B., Siekert, R. G., and Keith, H. M. (1958). Multiple sclerosis in children. Pediatrics, 21, 703-7j9.

Gallineck, A., and Kalinowsky, L. B. (1958). Psychiatric aspects of multiple sclerosis. Dis. nerv. Syst., 19, 77-80.

Heath, R. G., Monroe, R. R., and Mickle, W. A. (1955). Stimulation of the amygdaloid nucleus in a schizophrenic patient. Amer. J. Psychiat., 111, 862-863.

Heimburger, R. F., Whitlock, C. C., and Kalsbeck, J. E. (1966). Stereotaxic amygdalotomy for epilepsy with aggressive behaviour. J. Amer. med. Ass., 198, 741-745.

Howes, S. F. H. (1927). Psychoses with multiple sclerosis. Boston med. surg. J., 196, 310-315.

Ingram, W. R. (1956). The hypothalamus. Clin. Symp., 8, 117-156.

Ingram, (1958). Modification of learning by lesions and stimulation in the diencephalon and related structures, pp. 535-544 in Reticular Formation of the Brain. Edited by Jasper, H. H., et al. Little, Brown and Co.: Boston and Toronto.

Isler, W. (1961). Multiple sclerosis in childhood. Helv. Paediat. Acta, $16,412-431$.

Ivers, R. R., and Goldstein, N. P. (1963). Multiple sclerosis: a current appraisal of symptoms and signs. Proc. Mayo Clin., 38, 457466.

John, E. (1951). Schädel-Hirntrauma, Vegetatives Nervensystem and Ausnahmezüstande. Acta neuroveg. (Wien), 2, 163-170.

Kaada, B. R., Andersen, P., and Jansen, J. (1954). Stimulation of the amygdaloid nuclear complex in unanesthetized cat. Neurology (Minneap.), 4, 48-64.

Kennedy, C., and Carter, S. (1961). Relation of optic neuritis to multiple sclerosis in children. Pediatrics, 28, 377-387.

Kuriowa, Y., Inoue, K., Araki, S., and Inoue, K. (1962). Multiple sclerosis occurred in childhood. Kyushu J. med. Sci., 13, 193198.

Langworthy, O. R., Kolb, L. C., and Androp, S. (1941). Disturbances of behavior in patients with disseminated sclerosis. Amer. J. Psychiat., 98, 243-249.

Low, N. L., and Carter, S. (1956). Multiple sclerosis in children. Pediatrics, 18, 24-30.

McAlpine, D., Compston, N. D., and Lumsden, C. E. (1955). Multiple Sclerosis, pp. 105-110. E. \& S. Livingstone: Edinburgh and London.

—, Lumsden, C. E., and Acheson, E. D. (1965). Multiple Sclerosis. A Reappraisal, pp. 133-141. Williams and Wilkins: Baltimore, Md.

MacLean, P. D. (1954). The limbic system and its hippocampal formation: studies in animals and their possible application to man. J. Neurosurg., 11, 29-44.

Müller, R. (1949). Studies on disseminated sclerosis, with special reference to symptomatology, course and prognosis. Acta med. scand., 132, (Suppl. no. 222), 5-214.

Můr, J., Kümpel, G., and Dostàl, S. (1966). An anergic phase of disseminated sclerosis with psychotic course. Confin. neurol. (Basel), 28, 37-49.

Narabayashi, H., and Uno, M. (Tokyo, 1966). Long-range results of stereotaxic amygdalotomy for behaviour disorders. Ibid., 27, 168-171.

Paine, R. S., Goodman, J., Houck, J. C., and Javedan, M. (1963). Grand rounds: disseminated sclerosis. Clin. Proc. Child. Hosp. (Wash.), 19, 215-224.

Papez, J. W. (1958). The visceral brain, its components and connections, in Reticular Formation of the Brain. Edited by Jasper, H. H., et al. Little, Brown \& Co.: Boston and Toronto.

Parker, N. (1956). Disseminated sclerosis presenting as schizophrenia. Med. J. Aust., 1, 405-407.

Ross, A. T., and Reitan, R. M. (1955). Intellectual and affective functions in multiple sclerosis. Arch. Neurol. Psychiat. (Chic.), 73, 663-677.

Sawa, M., Ueki, Y., Arita, M., and Harada, T. (1954). Preliminary report on the amygdaloidectomy on the psychotic patients with interpretation of oral-emotional manifestation in schizophrenics. Folia psychiat. neurol. jap., 7, 309-329.

Sugar, C., and Nadell, R. (1943). Mental symptoms in multiple sclerosis. J. nerv. ment. Dis., 98, 267-280.

Teitelbaum, H. A., Hall, B. H., and Phillips, R. E. (1952). Psychosomatic aspects of multiple sclerosis. Arch. Neurol. Psychiat. (Chic.), 67, 535-544.

Woringer, E., Thomalske, G., and Klinger, J. (1953). Les rapports anatomiques du noyau amygdalien et la technique de son extirpation neurochirurgicale. Rev. neurol., 89, 553-560. 